AperTO - Archivio Istituzionale Open Access dell'Università di Torino

\title{
Acute renal infarction: a single center experience
}

\section{This is the author's manuscript}

Original Citation:

\section{Availability:}

This version is available http://hdl.handle.net/2318/1545600

since 2019-02-13T15:39:22Z

Published version:

DOI:10.1007/s40620-015-0259-0

Terms of use:

Open Access

Anyone can freely access the full text of works made available as "Open Access". Works made available under a Creative Commons license can be used according to the terms and conditions of said license. Use of all other works requires consent of the right holder (author or publisher) if not exempted from copyright protection by the applicable law. 
This is the author's final version of the contribution published as:

Mesiano, Paola; Rollino, Cristiana; Beltrame, Giulietta; Ferro, Michela; Quattrocchio, Giacomo; Fenoglio, Roberta; Pozzato, Marco; Cecere, Pasqualina; Forneris, Giacomo; Bazzan, Mario; Macchia, Gianluca; Roccatello, Dario. Acute renal infarction: a single center experience. JN. JOURNAL OF NEPHROLOGY. None pp: 1-5. DOI: $10.1007 / \mathrm{s} 40620-015-0259-0$

The publisher's version is available at:

http://link.springer.com/content/pdf/10.1007/s40620-015-0259-0

When citing, please refer to the published version.

Link to this full text:

http://hdl.handle.net/2318/1545600 


\section{Acute renal infarction: a single center experience.}

Mesiano $\mathrm{P}^{1}$, Rollino $\mathrm{C}^{2}$, Beltrame $\mathrm{G}^{2}$, Ferro $\mathrm{M}^{2}$, Quattrocchio $\mathrm{G}^{2}$, Fenoglio $\mathrm{R}^{2}$, Pozzato $\mathrm{M}^{2}$, Cecere $\mathrm{P}^{2}$, Forneris $\mathrm{G}^{2}$, Bazzan $\mathrm{M}^{3}$, Macchia $\mathrm{G}^{4}$, Roccatello $\mathrm{D}^{2,5,6}$.

1Nephrology and Dialysis Unit, San Giovanni Bosco Hospital, Piazza del Donatore di Sangue 3, 10154, Turin, Italy.paola.mesiano@gmail.com.

2Nephrology and Dialysis Unit, San Giovanni Bosco Hospital, Piazza del Donatore di Sangue 3, 10154, Turin, Italy.

3Hematology Unit, San Giovanni Bosco Hospital, Piazza del Donatore di Sangue 3, 10154, Turin, Italy.

4Radiology, San Giovanni Bosco Hospital, Piazza del Donatore di Sangue 3, 10154, Turin, Italy.

5Center of Research on Immunopathology and Rare Diseases, San Giovanni Bosco Hospital, Piazza del Donatore di Sangue 3, 10154, Turin, Italy.

6University of Turin, Turin, Italy.

Abstract

Background

Acute renal infarction is a rare condition whose diagnosis is often delayed. Major risk factors include atrial fibrillation, valvular or ischemic heart disease, renal artery thrombosis/dissection and coagulopathy.

\section{Methods}

We reviewed the medical records of 18 patients admitted to our Nephrology Department between 1999 and 2015 for acute renal infarction diagnosed by computed tomography. Tc-99m dimercaptosuccinic acid (DMSA) scintigraphy was performed in some patients during follow-up to assess parenchymal lesions and estimate differential kidney function.

\section{Results}

Mean age was 59.8 years. Major associated risk factors included hypertension (44\%), obesity (33\%), atrial fibrillation (28\%), peripheral vascular disease (17\%), smoking (17\%), prior thromboembolic event (11\%), diabetes $(11 \%)$, estroprogestinic therapy $(11 \%)$. Seventy-two percent of patients presented with flank pain. Mean serum creatinine was $1.2 \pm 0.6 \mathrm{mg} / \mathrm{dl}$. Acute kidney injury occurred as the initial manifestation in two patients. Patients were managed conservatively, with low molecular weight heparin (83\%) or aspirin (11\%). At the end of follow-up serum creatinine was $1.1 \pm 0.3 \mathrm{mg} / \mathrm{dl}$; one patient remained on chronic hemodialysis. $58 \%$ of patients who underwent renal scintigraphy after a median of 8 months had a reduced contribution of the previously affected kidney to total renal function.

\section{Conclusion}

Risk factors associated with the development of chronic kidney disease following renal infarction are unknown. In our subjects, renal function remained stable in all but one patient who developed end stage renal disease. Further studies should focus on etiology and evolution of kidney function in patients with acute renal infarction. 
Introduction

Acute renal infarction, due to an abrupt interruption of renal arterial flow, is a rare condition with an estimated incidence of 0.004-0.007\% in the Emergency Department setting [1, 2]. Non-specific clinical presentation mimicking other pathologic states (e.g. urolithiasis, acute pyelonephritis, other acute abdominal diseases) often causes a delay in the diagnosis, which may increase the risk of impaired renal failure [3-5]. Radiologic diagnosis of renal infarction is based on enhanced contrast computed tomography (CT), which typically indicates the presence of a wedge-shaped hypodense area in the peripheral region [2]. Major risk factors for renal infarction include atrial fibrillation, valvular or ischemic heart disease, renal artery thrombosis/dissection and coagulopathy. Etiology remains unknown in many cases [4, 6, 7]. We describe the clinical and radiological characteristics and renal prognosis of 18 patients with acute renal infarction.

\section{Methods}

We retrospectively reviewed the medical records of 18 patients (13 male and 5 female) who were admitted to our Nephrology Department between 1999 and 2015 for acute renal infarction diagnosed by CT scan and subsequently followed up as outpatients. Demographic, clinical and laboratory data at the time of initial clinical presentation were collected for each patient. Follow-up imaging and laboratory data were collected when available. Continuous data were expressed as mean \pm standard deviation (SD) or median (range), dichotomous values as percentage. Renal infarction was defined as a triangular-shaped peripheral area of the renal parenchyma that remained hypodense after injection of contrast medium and showed no enhancement [2]. Renal infarcts were classified as focal in the case of a single wedge-shaped lesion, multifocal (two or more lesions) and global (if more than $50 \%$ of the renal tissue was uniformly involved) [8]. An increase in C-reactive protein (CRP) levels was defined as a CRP level above $0.5 \mathrm{mg} / \mathrm{dl}$. Elevated lactate dehydrogenase (LDH) levels and white blood cell (WBC) counts were defined as values exceeding the upper normal limit. Proteinuria was defined as a total urinary protein excretion of more than $150 \mathrm{mg} /$ day. The estimated glomerular filtration rate (eGFR) was calculated from baseline serum creatinine using the four-variable Modification of Diet in Renal Disease Study (MDRD) formula. Renal failure was defined as eGFR <60 $\mathrm{ml} / \mathrm{min}$ [9]. Acute kidney injury (AKI) was defined as a serum creatinine level increased by more than 0.3 $\mathrm{mg} / \mathrm{dl}$ or $150 \%$ over baseline level within $48 \mathrm{~h} \mathrm{[10]}$. Arterial hypertension was defined as systolic blood pressure (SBP) greater than $140 \mathrm{mmHg}$ and/or diastolic blood pressure (DBP) greater than $90 \mathrm{mmHg}$, or as subjects who were receiving antihypertensive therapy at the time of examination. Tc-99m dimercaptosuccinic acid (DMSA) scintigraphy was performed in some patients during follow-up to assess parenchymal lesions and estimate differential kidney function.

Results

Eight patients were diagnosed between 1999 and 2006, while the remaining 10 were diagnosed between 2007 and 2015. Patients' age ranged from 29 to 86 years, with an average of 59.8 years. Potential risk factors associated to thromboembolism included hypertension (44\%), peripheral vascular disease (17\%), ischemic heart disease $(0.5 \%)$, atrial fibrillation (28\%), prior thromboembolic event $(11 \%)$, coagulation dysfunction or hematologic disease $(11 \%$ had mild, uncomplicated spherocytosis and heterozygous prothrombin G20210A mutation). One patient had undergone previous cardiac surgery for atrial myxoma, $33 \%$ of patients were obese, $11 \%$ were diabetic, $17 \%$ were current smokers, one had a history of cocaine abuse, and $11 \%$ were on estroprogestinic therapy. Two patients had experienced a previous renal infarct. There were four patients with solitary kidney. Demographic features and risk factors are summarized in Table 1. At the time of diagnosis, $72 \%$ of patients presented with colicky flank pain and $17 \%$ with diffuse abdominal pain. Two patients experienced a painless renal infarction: one of them was paraplegic with recurrent urinary tract infections due to neurogenic bladder and previous infarction of the contralateral kidney; in the second case, the renal infarction was fortuitously revealed during a CT scan performed for a suspicion of a pheochromocytoma. Associated symptoms included macroscopic hematuria (17\%), hyperthermia (28\%) and oliguria $(11 \%)$. The mean time between onset of symptoms and diagnosis of renal infarction was $3.5 \pm 5$ 
days. New onset arterial hypertension or worsening of previous arterial hypertension was observed in half of the patients. Mean systolic arterial pressure was $147.7 \pm 18.2 \mathrm{mmHg}$, diastolic $83.2 \pm 9.5 \mathrm{mmHg}$. Echocardiogram showed left ventricular hypertrophy in 5/18 patients, left atrial dilatation in 5/18 patients, left ventricular dysfunction in one patient and diastolic dysfunction in 2 patients. Mean serum creatinine on admission was $1.2 \pm 0.6 \mathrm{mg} / \mathrm{dl}$, with maximum values during observation of $1.8 \pm 1.8 \mathrm{mg} / \mathrm{dl}$, proteinuria 0.2 $\pm 0.1 \mathrm{~g} /$ day. One-third of the patients had microhematuria. Leukocytosis was recorded in $67 \%$ of patients (mean values $10.6 \pm 3.9 \mathrm{~mm} 3$ ), high $\mathrm{LDH}$ concentrations in $89 \%$ (mean values $1441 \pm 778 \mathrm{IU} / \mathrm{l}$ ), and augmented CRP levels in $72 \%$ (mean values $11 \pm 11 \mathrm{mg} / \mathrm{dl}$ ). AKI occurred as the initial manifestation of the renal infarction in two patients, one of whom required chronic hemodialysis treatment. Six out of 13 patients were found to have antiphospholipid antibodies at diagnosis (anti- $\beta 2$ GPI antibodies in three, anticardiolipin antibodies in two, lupus anticoagulant in one); however, after 12 weeks these antibodies were still detectable in only one subject. Renal infarct affected the right kidney in $9 / 18$ patients $(50 \%)$ and the left kidney in $7 / 18$ (39\%), while bilateral renal involvement was present in 2/18 (11\%). Among patients with unilateral renal involvement $(\mathrm{n}=16), 7$ had wedge-shaped focal infarcts, whereas 9 patients presented multifocal lesions and 2 patients displayed global renal infarction (Fig. 1). Perirenal stranding with thickening of the Gerota fascia was described in $7 / 18$ patients (39\%). Renal artery abnormalities were present in $4 / 18$ cases $(22 \%)$, i.e. fibromuscular dysplasia (Fig. 2) in 2 and dissection in 2 cases involving the right renal artery and a distal branch of the right renal artery, respectively. In one-third of patients, thrombosis of the renal artery or one of its branches (without anatomic wall alterations) was the only pathologic feature. None of the patients underwent supplementary endovascular radiologic procedures. Thirty-five percent of patients underwent more than one CT during the first month after diagnosis, including two who had an initially non diagnostic native CT scan evaluation and thus underwent a subsequent contrast CT within $24 \mathrm{~h}$ that revealed the renal infarction. Three other patients had a second exam to evaluate the extent of the infarct (at $48 \mathrm{~h}, 15$ and 12 days, respectively). The results showed dissection of the renal artery and previously absent perirenal inflammation in the first patient. The second subject had a reduction of infarct size but tendency to colliquation, while the third showed stability of the lesions. One patient, with solitary kidney secondary to a previous malignancy, underwent three imaging evaluations: an initial non-contrast one showed perirenal stranding with thickening of the Gerota fascia; 5 days later a CT urography to exclude malignancy revealed a renal infarct of the solitary kidney, and a third evaluation, 12 days after the first, was a CT angiography highlighting thrombosis and dissection of a branch of the right renal artery (Fig. 3). Four patients, all but one with atrial fibrillation, experienced concomitant infarcts in other organ systems (stroke or splenic infarct). All patients were managed conservatively without surgical or endovascular intervention, 15/18 (83\%) received therapeutic doses of low molecular weight heparin (LMWH), 2/18 (11\%) were given aspirin alone; one patient, with a small focal ischemia, did not receive any anticoagulant/antiplatelet treatment because of concomitant pheochromocytoma-related severe hypertension. Among the 15 patients who were initially treated with LMWH, long-term oral anticoagulation was later started in 7 patients, while 4 patients remained on aspirin alone; of the remaining 4 patients, in 3 cases the outcome was unknown while 1 ongoing case was still on LMWH. At the end of follow-up (median 15 months, range 0-150), serum creatinine was $1.1 \pm 0.3$ $\mathrm{mg} / \mathrm{dl}$; one patient remained on chronic hemodialysis.

Thirty-nine percent of patients (7/18) underwent renal scintigraphy after a median of 8 months (range 4120), $58 \%$ of whom showed an impaired contribution of the previously affected kidney to total renal function $(38.3 \pm 10.8 \%)$. In 4/7 patients renal scintigraphy detected focal areas of reduced tracer uptake at the site of the previous infarction and an irregular kidney outline.

Discussion

Renal infarction is an uncommon disease whose early diagnosis remains a challenge. Clinical suspicion of other common diseases, in particular acute pyelonephritis and nephrolithiasis, may delay the diagnosis. Indeed, using an unenhanced CT scan to rule out urolithiasis, renal infarction may be missed [6]. Thirty-five percent of our patients underwent more than one CT during a brief period of observation. Three of them who 
had an initially non diagnostic native CT scan evaluation underwent a subsequent contrast-enhanced CT within a median of $56 \mathrm{~h}$ which revealed the renal infarction. When contrast $\mathrm{CT}$ allows a definite diagnosis of renal infarction to be made, an angiographic study of the renal vasculature is recommended in order to evaluate the presence of arterial abnormalities and localize the site of embolization or thrombosis. Angio-CT was performed in $72 \%$ of our patients. Although perfusion scans were not carried out in the remaining patients, and we could not definitively exclude vascular abnormalities, in these cases the etiology was cardioembolic.

In two patients, angio-CT revealed the presence of renal artery dissection concomitant with intraluminal thrombi. Renal artery dissection, a rare entity that is often related to predisposing factors such as fibromuscular dysplasia, atherosclerosis, malignant hypertension, and hereditary connective tissue disorders [11], appeared to be spontaneous in our patients, in whom the therapeutic choice consisted of watchful waiting without surgical or endovascular intervention.

Perirenal stranding and thickening of the Gerota fascia were demonstrated in $39 \%$ of patients, $71 \%$ of whom presented multifocal lesions. Although these radiologic patterns are less common in renal infarction as compared to acute pyelonephritis, an inflammatory reaction may follow the vascular insult to the renal parenchyma [8].

Renal infarction commonly occurs in a setting of heart disease or thromboembolic tendency. According to previous series [7], $50 \%$ of our patients had an idiopathic renal infarction. Renal artery abnormalities were present in $22 \%$ of patients, while the etiology was cardioembolic in $28 \%$. Clinical presentation was confirmed as being non-specific.

The reported incidence of AKI ranges from 0 to $60 \%$ in study populations of different sizes, and seems to be related to infarct size, degree of proteinuria, the presence of microscopic hematuria and pre-existing chronic renal failure [5]. AKI occurred in two of our patients (one of whom had a global infarction and a contralateral atrophic kidney) and definitively required maintenance hemodialysis.

Risk factors associated with the development of chronic kidney disease (CKD) following renal infarction are unknown. In our subjects, renal function remained stable at the end of follow-up in all but one patient who developed end-stage renal disease. Fifty-eight percent of patients who underwent renal scintigraphy during follow-up showed a reduced contribution of the previously injured kidney to total renal function, while overall renal function assessed with serum creatinine and eGFR remained stable.

Our study has some limitations: first, some laboratory data are lacking due to the retrospective nature of the analysis and incomplete follow-up; second, the sample size is too limited to stratify patients on the basis of, for example, the etiology of renal infarction. However, we were able to evaluate the contribution of the affected kidney to overall renal function over a long period of follow-up, albeit in a limited number of patients. Further studies, designed in a prospective and multicenter manner, should focus on the etiology and evolution of kidney function in patients with acute renal infarction.

\section{References}

1. Huang CC, Lo HC, Huang HH, Kao WF, Yen DH, Wang LM, Huang CI, Lee CH (2007) ED presentations of acute renal infarction. Am J Emerg Med 25(2):164-169

2. Domanovits H, Paulis M, Nikfardjam M, Meron G, Ku“ rkciyan I, Bankier AA, Laggner AN (1999) Acute renal infarction. Clinical characteristics of 17 patients. Medicine (Baltimore) 78(6):386-394

3. Lessman RK, Johnson SF, Coburn JW, Kaufman JJ (1978) Renal artery embolism: clinical features and long-term follow-up of 17 cases. Ann Intern Med 89(4):477-482 
4. Bourgault M, Grimbert P, Verret C, Pourrat J, Herody M, Halimi JM, Karras A, Amoura Z, Jourde-Chiche $\mathrm{N}$, Izzedine H, Franc sois H, Boffa JJ, Hummel A, Bernadet-Monrozies P, Fouque D, Canoul"-Poitrine F, Lang P, Daugas E, Audard V (2013) Acute renal infarction: a case series. Clin J Am Soc Nephrol 8(3):392398

5. Bae EJ, Hwang K, Jang HN, Kim MJ, Jeon DH, Kim HJ, Cho HS, Chang SH, Park DJ (2014) A retrospective study of short- and long-term effects on renal function after acute renal infarction. Ren Fail 36(9):1385-1389

6. Antopolsky M, Simanovsky N, Stalnikowicz R, Salameh S, Hiller N (2012) Renal infarction in the ED: 10-year experience and review of the literature. Am J Emerg Med 30(7):1055-1060

7. Bolderman R, Oyen R, Verrijcken A, Knockaert D, Vanderschueren S (2006) Idiopathic renal infarction. Am J Med 119(4):356

8. Suzer O, Shirkhoda A, Jafri SZ, Madrazo BL, Bis KG, Mastromatteo JF (2002) CT features of renal infarction. Eur J Radiol 44(1):59-64

9. Levey AS, Bosch JP, Lewis JB, Greene T, Rogers N, Roth D (1999) A more accurate method to estimate glomerular filtration rate from serum creatinine: a new prediction equation. Modifi- cation of Diet in Renal Disease Study Group. Ann Intern Med 130(6):461-470

10. Mehta RL, Kellum JA, Shah SV, Molitoris BA, Ronco C, Warnock DG, Levin A (2007) Acute kidney injury network: acute kidney injury network: report of an initiative to improve outcomes in acute kidney injury. Crit Care 11(2):R31

11. Stawicki SP, Rosenfeld JC, Weger N, Fields EL, Balshi JD (2006) Spontaneous renal artery dissection: three cases and clinical algorithms. J Hum Hypertens 20(9):710-718 
Table 1: Demographic data and underlying disease at the time of diagnosis of renal infarction

\begin{tabular}{|c|c|}
\hline Age at diagnosis (years) & $59.8 \pm 16.8$ \\
\hline $\mathrm{M} / \mathrm{F}$ & $13 / 5$ \\
\hline Africans/Caucasians & $1 / 17$ \\
\hline \multicolumn{2}{|l|}{ Underlying disease, $\mathrm{n}$} \\
\hline Arterial hypertension & 8 \\
\hline Obesity & 6 \\
\hline Atrial fibrillation & 5 \\
\hline Solitary kidney & 4 \\
\hline Smoking & 3 \\
\hline Peripheral vascular disease & 3 \\
\hline Prior thromboembolic event & 2 \\
\hline Coagulation/hematologic disorders & 2 \\
\hline Pevious renal infarct & 2 \\
\hline Estroprogestinic therapy & 2 \\
\hline Diabetes & 2 \\
\hline Ischemic heart disease & 1 \\
\hline Cocaine abuse & 1 \\
\hline Previous cardiac surgery (atrial myixoma) & 1 \\
\hline
\end{tabular}




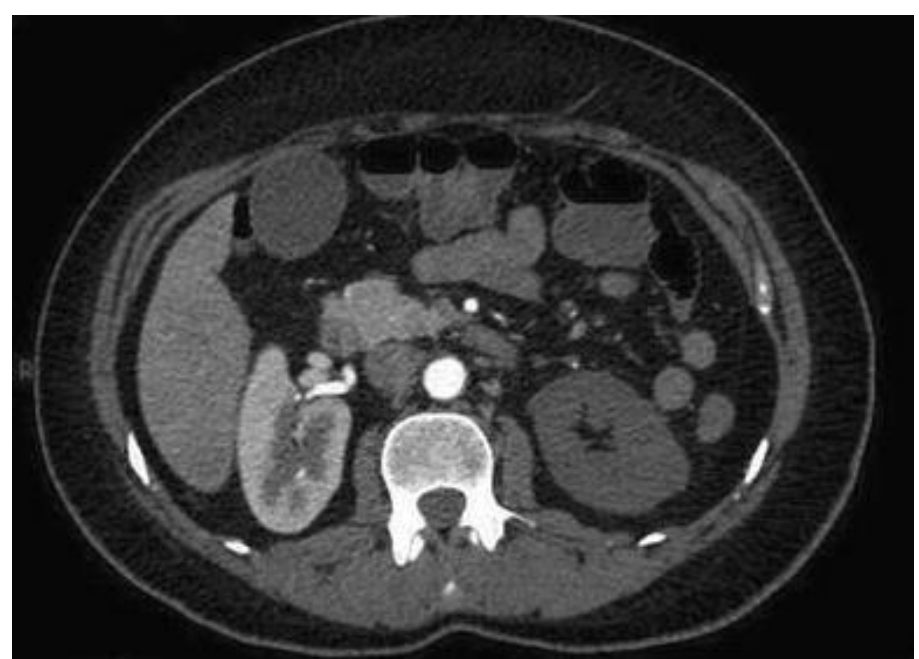

Fig. 1: Global infarction of the left kidney
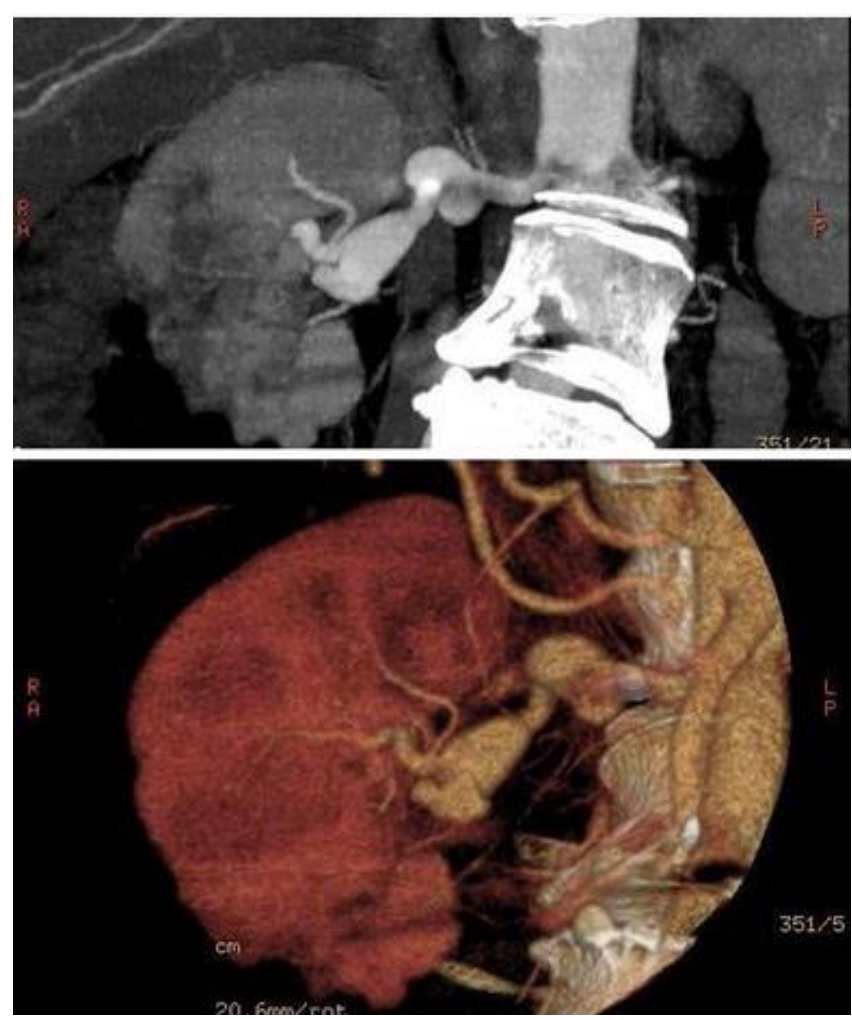

Fig. 2: Composite picture of renal computed tomography angiography with 3D reconstruction images. Segmental renal infarctual lesions of a right solitary kidney (previous contralateral nephrectomy for global renal infarction) and segmental renal artery aneurysm secondary to fibromuscular dysplasia 

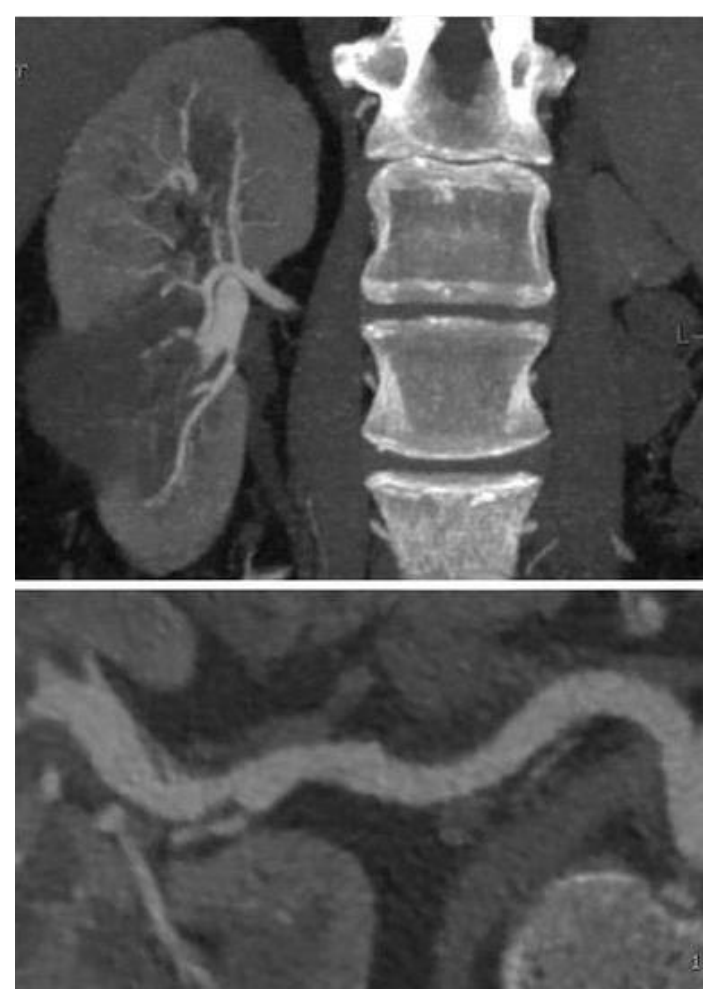

Fig. 3: Composite picture of renal computed tomography angiography. Renal infarction of a solitary kidney, with thrombosis and dissection of a branch of the right renal artery 